\title{
PENGARUH VARIASI KOMBINASI KONSENTRASI SURFAKTAN NON IONIK (SPAN 60 DAN PEG-40 HCO) TERHADAP STABILITAS FISIK MIKROEMULSI KOENZYM QIO
}

\section{Effect Of Combination Variation Of Non Ionic Surfactant Concentration (Span 60 And Peg-40 Hco) On The Physical Stability Of Koenzym Q 10 Microemulsion}

\section{Silvi Ayu Wulansari"*}

Umarudin ${ }^{2}$

*IAkademi Farmasi Surabaya, Surabaya, Jawa Timur, Indonesia

${ }^{2}$ Akademi Farmasi Surabaya, Surabaya, Jawa Timur, Indonesia

*email: silviayu25@gmail.com

\begin{abstract}
Abstrak
Koenzim Q10 merupakan senyawa yang berfungsi sebagai antioksidan dengan berat molekul yang cukup besar $863,36 \mathrm{~g} / \mathrm{mol}$ serta memiliki sifat lipofilik. Hal ini yang membuat koenzim Q10 perlu diformulasikan untuk memperbaiki kelarutan bahan dan sistem penghantaran di dalam kulit. Penelitian ini bertujuan untuk mengetahui pengaruh variasi kombinasi konsentrasi surfaktan non ionik (span 60 dan PEG-40 HCO) terhadap stabilitas fisik mikroemulsi koenzim Q10. Pada penelitian ini Koenzim QI0 diformulasikan dalam sediaan mikroemulsi tipe miyak dalam air. Minyak yang digunakan sebagai fase minyak adalah rice bran oil dengan kombinasi surfaktan span 60 dan PEG-40 HCO dan ethanol $96 \%$ sebagai kosurfaktan. mikroemulsi dibuat dalam 4 formula mikoemulsi yaitu FI, F2, F3 dan F4, Setiap formula dilakukan 3 replikasi. sediaan mikroemulsi dievaluasi setelah 24 jam setelah sediaan selesai dibuat, pengamatan yang dilakukan meliputi organoleptis (bentuk, warna dan fase yang terbentuk), $\mathrm{pH}$, viskositas, ukuran droplet, zeta potensial dan polidispersity index pada sebelum dan sesudah uji sentrifugasi dengan $10.000 \mathrm{rpm}$ selama 30 menit. Data penelitian diolah secara statistik dengan menggunakan analisis kruskal-Wallis dan uji lanjutan Mann-Whitney. Hasil penelitian menunjukkan bahwa konsentrasi surfaktan berpengaruh terhadap karakteristik fisik (viskositas, ukuran droplet, zeta potensial dan polydispersity index) dengan hasil beda signifikan $(p<0,05)$ sedangkan konsentrasi surfaktan tidak berpengaruh nyata terhadap $\mathrm{pH}(\mathrm{p}>0,05)$.
\end{abstract}

\section{Kata Kunci: \\ Abstract}

Mikroemulsi

Surfaktan

Koenzim Q10

Rice Brand Oil

Span 60

Keywords:

Microemulsion

Surfactan

Coenzime

Rice Brand Oil

Span 60

\begin{abstract}
Coenzyme $Q 10$ is a compound that functions as an antioxidant with a large molecular weight of $863.36 \mathrm{~g} / \mathrm{mol}$ and has lipophilic properties. This makes coenzyme Q 10 need to be formulated to improve the solubility of the material and the delivery system in the skin. This study aims to determine the effect of various combinations of non-ionic surfactant concentrations (span 60 and PEG-40 HCO) on the physical stability of microemulsions. In this study Coenzyme Q10 was formulated in oil-type microemulsion preparations in water. The oil used as the oil phase is rice bran oil with a combination of surfactant span 60 and PEG-40 HCO and $96 \%$ ethanol as a cosurfactant. microemulsion was made in 4 micoemulsion formulas namely Fl, F2, F3 and F4, each formula was made 3 replications. Microemulsion preparations were evaluated after 24 hours after the preparations were made, observations made included organoleptic (shape, color and phase formed), $\mathrm{pH}$, viscosity, droplet size, zeta potential and polydispersity index before and after centrifugation test with 10,000 rpm for 30 minutes. The research data were processed statistically using the Kruskal-Wallis analysis and Mann-Whitney follow-up tests. The results showed that the surfactant concentration affected physical characteristics (viscosity, droplet size, zeta potential and polydispersity index) with a significantly different result $(p<0.05)$ but the surfactant concentration did not affect the $\mathrm{pH}$ with the results not significantly different ( $p>$ $0,05)$.
\end{abstract}

(c) year The Authors. Published by Institute for Research and Community Services Universitas Muhammadiyah Palangkaraya. This is Open Access article under the CC-BY-SA License (http://creativecommons.org/licenses/by-sa/4.0/). DOI: https://doi.org// 0.33084/jsm.vxix.xxx.

\section{PENDAHULUAN}

Koenzim Q10 merupakan senyawa yang berfungsi sebagai antioksidan dengan berat molekul yang cukup besar $863,36 \mathrm{~g} / \mathrm{mol}$ serta memiliki sifat lipofilik. Koenzym QIO dapat menangkal kerusakan akibat radikal bebas dan memberikan perlindungan yang signifikan terhadap kerusakan membrane sel akibat 
UVA. Fungsi koenzym QI0 dapat membantu dalam mencegah kerusakan kolagen dan membantu proses produksi elastin untuk menghindari terjadinya keriput (Korkmaz et al, 2013). Selain itu, penggunaan koenzym QI0 secara berkala mampu mengurangi garis halus pada kulit atau dapat berfungsi sebagai antiaging Q 10 (Ramose-silva, et.al., 20I3). Namun pemanfaatan koenzym QI0 belum banyak di Indonesia, salah satu yang dapat menyebabkan adalah Koenzym QI0 memiliki beberapa kekurangan untuk diformulasi dalam bentuk sediaan topikal, seperti kelarutan dalam air yang rendah $(0,193$ $\mu \mathrm{g} / \mathrm{ml})$, berat molekul yang besar $(863,36 \mathrm{~g} / \mathrm{mol})$, dan memiliki sifat lipofilisitas yang tinggi yang membuat penetrasi Koenzym QIO dikulit rendah (Lucangioli \& Tripodi, 2012). Menurut hasil penelitian Korkmaz et al., 2013 bahwa Koenzym Q10 membutuhkan formulasi yang tepat sehingga menghasilkan produk dengan bioavailabilitas baik, efektif, dan dapat berpenetrasi ke dalam lapisan kulit yang dituju. Salah satu cara untuk meningkatkan penetrasi koenzym QI0 kedalam kulit adalah membuat dalam sistem penghantaran nanoemulsi (Bhatt \& Madhav, 20II). Kajian penelitian untuk sistem penghantaran sebagai pembawa yang efektif dari koenzim QIO dilakukan untuk mendapatkan produk dengan bioavailabilitas baik, efektif, dan dapat meningkatkan daya penetrasi ke dalam lapisan kulit (Shoviantari et al., 2017). Oleh karena itu perlu adanya penelitian formulasi mikroemuli koenzym QI0.

Mikroemulsi merupakan salah satu bagian dari nanoteknologi yang banyak dikembangkan pada nanomedicine dan nanodermatology yang dapat meningkatan kelarutan dan kinerja bahan obat baik sukar larut dalam air ataupun sebalikya (Singh et al., 2016). Mikroemulsi juga dapat memperbaiki penghantaran obat, karena dapat meningkatkan kelarutan dari obat yang sukar larut dalam air, hal mini dikarenakan ukuran partikel yang lebih kecil jika dibandingkan dengan emulsi konvesional (Erawati dkk, 2016). Mikroemulsi memiliki sifat yang stabil secara termodinamika dan transparan, serta merupakan dispersi dari minyak dan air yang distabilkan oleh lapis tipis (film) molekul ampifilik (surfaktan dan kosurfaktan) (Talegaonkar et al., 2008). Secara umum mikroemulsi tersusun dari fase air, fase minyak, kosurfaktan dan surfaktan (Dizaj, 20I3). Pemilihan fase minyak sangat mempengaruhi terhadap stabilitas nanoemulsi yang dihasilkan, dimana minyak yang mempunyai rantai pendek sampai sedang lebih stabil bila dibandingkan dengan rantai panjang (Khor et al., 20l4). Hal ini dikarenakan minyak yang memiliki rantai pendek sampai sedang lebih mudah dalam proses pemutusan rantai dan menghasilkan droplet lebih kecil sehingga dapat menghasilkan sediaan yang lebih jernih bila dibandingkan dengan minyak yang memiliki rantai panjang. Pemilihan minyak pada penelitian ini dengan menggunakan rice bran oil.

Rice bran oil merupakan minyak yang memiliki rantai sedang sehingga memungkinkan menghasilkan sediaan mikroemulsi yang stabil (Wulansari et al., 2019). Selain pemilihan minyak yang digunakan, pemilihan surfaktan yang digunakan juga mempengaruhi stabilitas sediaan mikroemulsi (Saifullah. et.,al., 2016). Surfaktan yang biasa digunakan merupakan golongan nonionik dikarenakan surfaktan nonionik memiliki sedikit sifat mengiritasi pada penggunaan topikal (Kakoty dan Gogoi, 2018). Pada penelitian ini dilakukan pembuatan mikroemulsi tipe air dalam minyak (water in oil) menggunakan minyak rice bran oil dengan variasi konsentrasi surfaktan non ionik sapan 60 dan PEG-40 HCO dan etanol 96 sebagai kosurfaktan. Penelitian ini bertujuan untuk mengetahui pengaruh variasi konsentrasi surfaktan non ionik sapan 80 dan PEG-40 HCO terhadap karakteristik fisik mikroemulsi (organoleptis, $\mathrm{pH}$, persen transmitan, ukuran droplet, zeta potensial dan polysidpersity index) dan stabilitas fisik mikroemulsi.

\section{METODOLOGI}

Metode penelitian ini dengan desain true experimental dengan jenis rancangan acak lengkap. Penelitian ini 
dilakukan di laboratorium teknologi farmasi Akademi Farmasi Surabaya. Bahan yang digunakan pada penelitian ini adalah Koenzim QI0 (Chemco), Span 60 (Rochem), PEG-40 Hydrogenated castor oil (Rochem), Etanol 96\% (Merck), Rice Bran Oil (Rochem), Asam Asetat Glasial (Merck), Sodium Asetat (Merck). Sedangkan alat yang digunakan pada penelitian ini berupa Timbangan analitik (ACIS AD-300i), pH meter, Gelas ukur (Pyrex), Beaker glass (Pyrex), Erlenmayer (Pyrex), Hotplate magnetic stirrer (SCILOGEX MS-H280-Pro), Spektrofotometer UV-Vis (Genesys IOS UV-Vis), Kaca arloji, Cawan porselen, Pipet tetes, Partikel Size Analizer. Berikut prosedur kerja pada penelitian ini adalah:

\section{Pembuatan Mikroemulsi}

Pembuatan mikroemulsi dengan cara minyak dedak (Race bran oil) dan Koenzim QI0 dimasukkan kedalam beaker glass aduk meggunakan magnetic stirrer dengan kecepatan $500 \mathrm{rpm}$ suhu $50^{\circ} \mathrm{C}$ selama 10 menit, tambahkan ethanol $96 \%$ aduk dengan kecepatan $500 \mathrm{rpm}$ suhu $50^{\circ} \mathrm{C}$ selama 5 menit, kemudian tambahkan PEG-40 Hydrogenated castor oil dan Span 60 aduk dengan kecepatan 700 rpm suhu $50^{\circ} \mathrm{C}$ selama 10 menit sampai campuran homogen (campuran I). Masukkan dapar asetat $\mathrm{pH}$ 4,2 \pm 0,2 kedalam beaker glass Campuran I di stirrer dengan keceptan $700 \mathrm{rpm}$ suhu $50^{\circ} \mathrm{C}$ selama 10 menit sampai homogen. Jika campuran telah homogen suhu dimatikan dengan tetap diaduk kecepatan $700 \mathrm{rpm}$ selama 10 menit. Berikut formula sediaan mikroemulsi QIO yang terlihat dibawah ini.

Tabel I. Formula Sediaan Mikroemulsi QIO

\begin{tabular}{|c|c|c|c|c|}
\hline Bahan & Fungsi & $\begin{array}{c}\text { FI } \\
\text { (\%) }\end{array}$ & $\begin{array}{c}\text { F2 } \\
\text { (\%) }\end{array}$ & $\begin{array}{c}\text { F3 } \\
\text { (\%) }\end{array}$ \\
\hline Q10 & Bahan Aktif & 0,3 & 0,3 & 0,3 \\
\hline Rice Brand Oil & Fase Minyak & 3,5 & 3,5 & 3,5 \\
\hline PEG-40 HCO & Surfaktan & 16 & 18 & 20 \\
\hline Span 60 & Surfaktan & 34 & 36 & 38 \\
\hline Ethonal 96 \% & Kosurfaktan & 3 & 3 & 3 \\
\hline Dapar Acetat pH 4,2 $\pm 0,2$ & Fase Air & \multicolumn{4}{|c}{ Ad I00 } \\
\hline
\end{tabular}

\section{Uji Stabilitas Mikroemulsi}

Uji stabilitas dipercepat dilakukan dengan menggunakan metode sentrifugasi. Pada pengujian sentrifugasi kecepatan yang digunakan adalah 10.000 rpm selama 30 menit ang ekivalen dengan efek gravitasi selama satu tahun. Setelah disentrifugasi dilakukan pengamatan karakteristik fisik mikroemulsi yang meliputi:

\section{a. Uji Organoleptis}

Pengujian dilakukan secara visual, mengamati bentuk, warna, dan fase yang terbentuk dari sediaan nanoemulsi.

\section{b. Uji pH}

Pengujian $\mathrm{pH}$ dilakukan dengan menggunakan $\mathrm{pH}$ meter Laqua Horiba Scientific yang telah dikalibrasi terlebih dahulu menggunakan dapar $\mathrm{pH}$ 4,00 dan 7,00 sebelum digunakan untuk mengukur mikroemulsi.

\section{c. Uji Persen Transmitan}

Pengujian persen transmitan dilakukan dengan spektrofotometer Uv-Vis.

\section{d. Uji Ukuran Droplet, Zeta Potensial dan} Polidispersity index

Pengujian ukuran droplet, zeta potensial dan polidispersity index mikroemulsi dilakukan dengan menggunakan alat Partikel Size Analizer. $2 \mathrm{ml}$ Sampel mikroemulsi dimasukkan dalam tabung reaksi kemudian diencerkan menggunakan aqua bidestilata sampai $10 \mathrm{ml}$, setelah itu di fortex terlebih dahulu selama 2 menit sebelum diamati. Data yang diamati menggunakan alata adalah diameter droplet rata-rata, zeta potensial dan Polydispersity index (PI).

Analisis data yang digunakan untuk mengetahui pengaruh konsentrasi surfaktan nonionik terhadap stabilitas fisik mikroemulsi menggunakan analisis kruskal-Wallis dengan uji lanjutan Mann-Whitney.

\section{HASIL DAN PEMBAHASAN}


Pengembangan sediaan farmasi dengan koenzym QIO diformulasikan menjadi mikroemulsi untuk meningkatkan kelarutan bahan koenzym QIO yang sukar larut dalam air (Bank et al, 20II) Pembuatan mikroemulsi dengan bahan aktif $0,3 \%$ koenzym QI0 menggunakan rice bran oil sebagai fase minyak untuk melarutkan koenzym Q10. Pada penelitian ini dilakukan variasi kombinasi konsentrasi surfaktan untuk menentukan formula mikroemulsi yang paling stabil pada uji stabilitas dipercepat, karena pemilihan jenis dan konsentrasi dari surfaktan, kosurfaktan, dan minyak sangat menentukan stabilitas dari mikroemulsi (Date and Nagarsenker, 2008). Uji stabilitas dipercepat mikroemulsi dilakukan dengan menggunakan metode sentrifugasi dengan kecepatan 10.000 rpm selama 30 menit. Uji organoleptis meliputi bentuk, warna dan fase yang terbentuk dilakukan pada masing - masing formula sebelum dan setelah diuji stabilitas dipercepat menggunakan metode sentrifugasi. Berikut hasil uji organoleptis yang terlihat pada Tabel dibawah ini.

Tabel 2. Hasil Uji Organoleptis

Pada Tabel diatas bahwa pengujian organoleptis sebelum disentrifugasi formula FI dan F2 memiliki organoleptis yang sama yaitu cairan berwarna kuning muda pucat, keruh, opak dan I fase. Pada formula F3 dan F4 memiliki organoleptis kuning muda pucat, jernih, transparent I fase. Namun sesudah disentrifugasi hanya formula F2 dan F3 saja yang tidak mengalami terjadi perubahan pemisahan fase. Beriku hasil uji $\mathrm{pH}$ yang terlihat dibawah ini.

Tabel 3. Hasil Uji pH pH (Rata - rata)

\begin{tabular}{cccc}
\hline Formula & Replikasi & $\begin{array}{c}\text { Sebelum } \\
\text { Sentrifugasi }\end{array}$ & $\begin{array}{c}\text { Setelah } \\
\text { Sentrifugasi }\end{array}$ \\
\hline FI & $\mathrm{I}, 2,3$ & 4,04 & 3,88 \\
F2 & $\mathrm{I}, 2,3$ & 4,26 & 4,09 \\
F3 & $\mathrm{I}, 2,3$ & 4,30 & 4,16 \\
F4 & $\mathrm{I}, 2,3$ & 4,38 & 4,16 \\
\hline
\end{tabular}

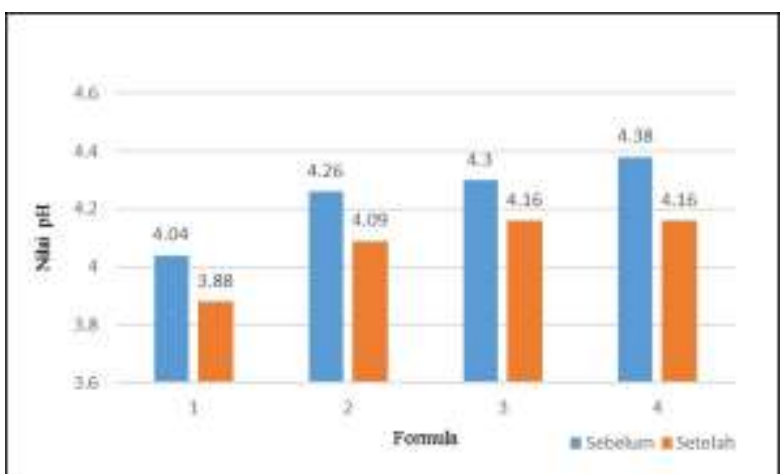

Gambar I. Histogram rerata $\mathrm{pH}$ mikroemulsi pada formula $\mathrm{FI}$, F2,F3, dan F4 data merupakan rerata 3 kali replikasi

Pada uji $\mathrm{pH}$ dilakukan pada masing - masing formula sebelum dan setelah diuji stabilitas dipercepat menggunakan metode sentrifugasi dapat dilihat pada tabel 3. Hasil pengukuran $\mathrm{pH}$ mikroemulsi formula $\mathrm{FI}$ saat awal terbentuk memiliki rerata $\mathrm{pH} 4,04$ dan sesudah sentrifugasi memiliki rerata $\mathrm{pH}$ sebesar3,88. Formula F2 saat awal terbentuk memiliki rerata $\mathrm{pH} 4,26$ dan sesudah sentrifugasi memiliki rerata $\mathrm{pH}$ 4,09. Formula F3 saat awal terbentuk memiliki rerata $\mathrm{pH}$ 4,30 dan sesudah sentrifugasi memiliki rerata $\mathrm{pH}$ 4,16. Formula F4 saat awal terbentuk memiliki rerata $\mathrm{pH} 4,38$ dan sesudah sentrifugasi memiliki rerata $\mathrm{pH} 4,16$, dari

\begin{tabular}{|c|c|c|c|}
\hline \multicolumn{4}{|c|}{ Pengamatan Visual } \\
\hline Formula & Replikasi & $\begin{array}{c}\text { Sebelum } \\
\text { Sentrifugasi }\end{array}$ & $\begin{array}{c}\text { Setelah } \\
\text { Sentrifugasi }\end{array}$ \\
\hline $\mathrm{FI}$ & $1,2,3$ & $\begin{array}{l}\text { Kuning muda } \\
\text { pucat, keruh, } \\
\text { opak, I fase }\end{array}$ & $\begin{array}{l}\text { Kuning muda } \\
\text { pucat, keruh, } \\
\text { opak, } 2 \text { fase }\end{array}$ \\
\hline F2 & $1,2,3$ & $\begin{array}{l}\text { Kuning muda } \\
\text { pucat, keruh, } \\
\text { opak, I fase }\end{array}$ & $\begin{array}{l}\text { Kuning muda } \\
\text { pucat, keruh, } \\
\text { opak, I fase }\end{array}$ \\
\hline F3 & $1,2,3$ & $\begin{array}{l}\text { Kuning muda } \\
\text { pucat, jernih, } \\
\text { transparant, I } \\
\text { fase }\end{array}$ & $\begin{array}{c}\text { Kuning muda } \\
\text { pucat, jernih, } \\
\text { transparant, I } \\
\text { fase }\end{array}$ \\
\hline $\mathrm{F} 4$ & $\mathrm{I}, 2,3$ & $\begin{array}{c}\text { Kuning muda } \\
\text { pucat, jernih, } \\
\text { transparant, I } \\
\text { fase }\end{array}$ & $\begin{array}{l}\text { Kuning muda } \\
\text { pucat,keruh, } \\
\text { opak, } 2 \text { fase }\end{array}$ \\
\hline
\end{tabular}
namun hasil masih masuk dalam spesifikasi $\mathrm{pH}$ sediaan kulit (pH 4-8) (Danimayostu dkk., 2017). Hasil nilai pH berdasarkan uji statistik 0,022 $\leq 0,05$ (beda signifikan) kruskal-wallis dan hasil sentrifugasi terhadap nilai $\mathrm{pH}$ Hasil statistik 0,034 $\leq 0,05$ (beda signifikan) Wilcoxon. 
Berikut hasil uji persen tranmitan yang terlihat dibawah ini.

Tabel 4. Hasil Uji Persen Tranmitan

\begin{tabular}{|c|c|c|c|}
\hline \multirow{2}{*}{ Formula } & \multirow{2}{*}{ Replikasi } & \multicolumn{2}{|c|}{$\begin{array}{c}\text { Persen Transmitan ( } \% \\
\text { Rata - rata) }\end{array}$} \\
\hline & & $\begin{array}{c}\text { Sebelum } \\
\text { Sentrifugasi }\end{array}$ & $\begin{array}{c}\text { Setelah } \\
\text { Sentrifugasi }\end{array}$ \\
\hline $\mathrm{FI}$ & $1,2,3$ & 59,14 & 28,38 \\
\hline F2 & $1,2,3$ & 66,22 & 62,88 \\
\hline F3 & $1,2,3$ & 80,90 & 79,91 \\
\hline F4 & $\mathrm{I}, 2,3$ & 89,47 & 30,34 \\
\hline
\end{tabular}

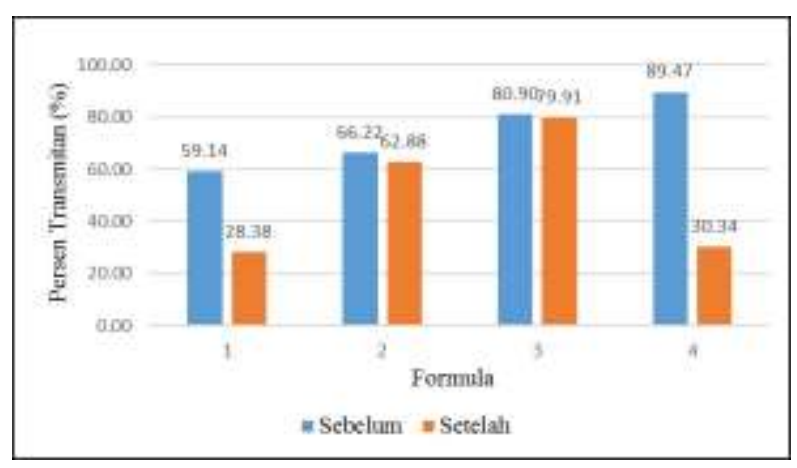

Gambar 2. Histogram rerata Persen Tranmitan mikroemulsi pada formula FI, F2,F3, dan F4 data merupakan rerata 3 kali replikasi

Pada pengujian persen transmitan dilakukan pada masing - masing formula sebelum dan setelah diuji stabilitas dipercepat menggunakan metode sentrifugasi dengan menggunakan 3 replikasi, data dapat dilihat pada tabel 4 . Hasil keempat formula (FI-F4) mengalami penurunan nilai persen transmitan. Dimana penurunan nilai mengindikasikan sediaan mengalami penurunan kejernihan setelah proses sentrifugasi. Pengaruh formula terhadap persen transmitan Hasil statistik 0,000 $\leq 0,05$ (beda signifikan) anova oneway. Pengaruh sentrifugasi terhadap persen transmitan Hasil statistik $0,008 \leq 0,05$ (beda signifikan) t-paired .Berikut hasil uji ukuran droplet yangn terlihat dibawah ini.

Tabel 5. Hasil Uji Ukuran droplet

\begin{tabular}{cccc}
\hline \multicolumn{3}{c}{ Ukuran Droplet (Rata - rata) $(\boldsymbol{\mu m})$} \\
\hline Formula & Replikasi & $\begin{array}{c}\text { Sebelum } \\
\text { Sentrifugasi }\end{array}$ & $\begin{array}{c}\text { Setelah } \\
\text { Sentrifugasi }\end{array}$ \\
\hline $\mathrm{FI}$ & $\mathrm{I}, 2,3$ & 10,38 & 14,10 \\
$\mathrm{~F} 2$ & $\mathrm{I}, 2,3$ & 8,47 & 7,47
\end{tabular}

\begin{tabular}{llll}
$F 3$ & $1,2,3$ & 7,22 & 6,39 \\
$F 4$ & $1,2,3$ & 4,76 & 7,44 \\
\hline
\end{tabular}

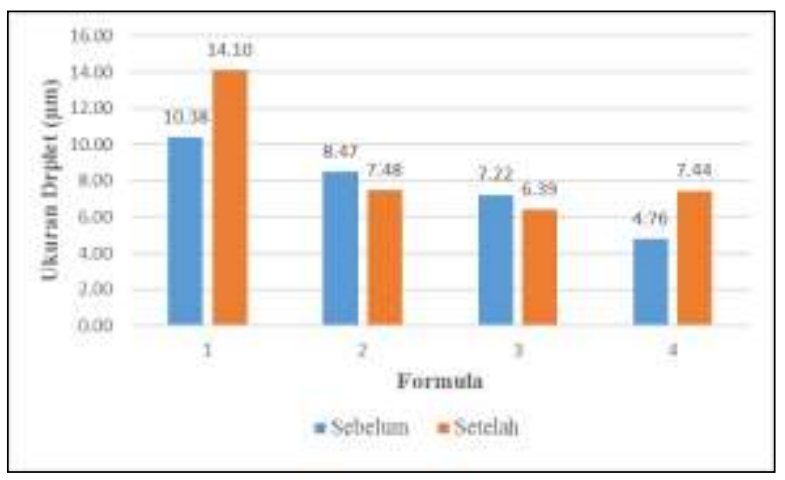

Gambar 3. Histogram rerata Ukuran droplet mikroemulsi pada formula FI, F2,F3,dan F4 data merupakan rerata 3 kali replikasi

Pengujian ukuran droplet dapat digunakan sebagai salah satu cara untuk mengetahui pemilhan surfaktan serta kombinasi dari surfaktan yang digunakan sudah sesuai untuk menghasilkan sediaan sesuai spesifikasi (Wulansari et al., 2019). Pengujian dilakukan pada masing - masing formula sebelum dan setelah diuji stabilitas dipercepat menggunakan metode sentrifugasi hasil dapat dilihat pada tabel 5. Hasil pengujian Ukuran Droplet mikroemulsi formula FI-F4 sebelum sentrifugasi memilki rentang nilai $(4,76-10,38)$ dan sesudah sentrifugasi $(6,39-\mid 4,10)$. Dari hasil diatas dapat diketahui ukuran droplet sesuai spesifikasi mikroemulsi yang memiliki ukuran retang antara 10-100 nm (Guan, et al., 2016). Pengaruh formula terhadap ukuran droplet Hasil statistik 0,000 $\leq 0,05$ (beda signifikan) anova oneway. Pengaruh sentrifugasi terhadap ukuran droplet Hasil statistik 0,158 $\geq 0,05$ (tidak beda signifikan). wilcoxon

Tabel 6. Hasil Uji Zeta Potensial Zeta Potensial (Rata - rata)

\begin{tabular}{cccc}
\hline Formula & Replikasi & $\begin{array}{c}\text { Sebelum } \\
\text { Sentrifugasi }\end{array}$ & $\begin{array}{c}\text { Setelah } \\
\text { Sentrifugasi }\end{array}$ \\
\hline FI & $\mathrm{I}, 2,3$ & $(-) 6, \mathrm{II}$ & $(-) 5.6 \mathrm{I}$ \\
F2 & $\mathrm{I}, 2,3$ & $(-) 46,07$ & $(-) 40,39$ \\
F3 & $\mathrm{I}, 2,3$ & $(-) 36,22$ & $(-) 33,67$ \\
F4 & $\mathrm{I}, 2,3$ & $(-) 7,14$ & $(-) 4,35$ \\
\hline
\end{tabular}




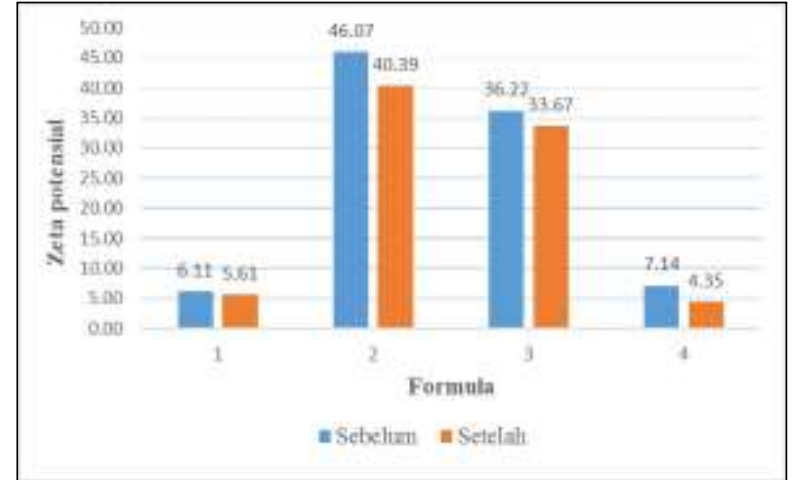

Gambar 4. Histogram rerata Zeta Potensial mikroemulsi pada formula FI, F2,F3, dan F4 data merupakan rerata 3 kali replikasi

Nilai zeta potensial jika lebih besar dari | $+25 \mathrm{mV}$ | atau | $-25 \mathrm{mV}$ | menunjukkan stabilitas sistem dari sistem sediaan mikroemulsi, jika zeta potensial rendah akan mendekati titik kritis flokulasinya dan menyebabkan fase yang terbentuk akan mudah mengalami perubahan menjadi 2 fase / pecah (Haidar, et. al., 2017). Hasil pengujian zeta potensial mikroemulsi dapat dilihat pada tabel 6. Formula FI-F4 sebelum sentrifugasi memilki rentang nilai | $-6,1$ I sampai $-46,07 \mathrm{mV}$ | dan sesudah sentrifugasi | -4,35 sampai $-40,39 \mathrm{mV}$ |. Semua hasil pengujian zeta potensial menunjukkan angka negatif (-), hal ini mengindikasikan bahwa mayoritas muatan permukaan droplet adalah anionik sehingga mengakibatkan penurunan muatan permukaan droplet menjadi negatif (Chuacharoen et al., 2019). Dari hasil diatas dapat diketahui F2 dan F3 memiliki nilai zeta potensial sesuai spesifikasi sediaan mikroemulsi yang baik, lebih besar dari | $-25 \mathrm{mV}$ | (Haidar, et. al., 2017). Pengaruh formula terhadap zeta potensial Hasil statistik $0,016 \leq 0,05$ (beda signifikan) kruskal-wallis. Pengaruh sentrifugasi terhadap zeta potensial Hasil statistik 0,0 I5 $\leq 0,05$ (beda signifikan). Wilcoxon.

Tabel 7. Hasil Uji Polidispersity Index Polidispersity Index (Rata - rata)

\begin{tabular}{cccc}
\hline Formula & Replikasi & $\begin{array}{c}\text { Sebelum } \\
\text { Sentrifugasi }\end{array}$ & $\begin{array}{c}\text { Setelah } \\
\text { Sentrifugasi }\end{array}$ \\
\hline FI & $I, 2,3$ & 0,0367 & 0,1438 \\
F2 & $I, 2,3$ & 0,0540 & 0,0366 \\
F3 & $I, 2,3$ & 0,0569 & 0,0956 \\
F4 & $I, 2,3$ & 0,0495 & 0,0677 \\
\hline
\end{tabular}

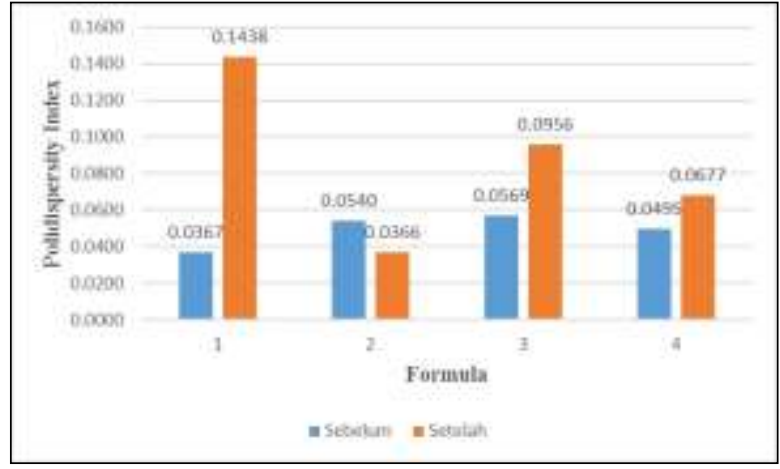

Gambar 5. Histogram rerata Polidispersity Index mikroemulsi pada formula FI, F2,F3,dan F4 data merupakan rerata 3 kali replikasi

Kriteria sediaan mikroemulsi yang baik adalah sediaan yang terbentuk I fase / monodisperse (Saifullah. et.,al., 2016). Hasil pengujian Polidispersity Index (PI) dari keenam formula dapat dilihat pada tabel 7 diperoleh rentang nilai $\mathrm{PI}(0,0367-0,569)$ dan sesudah sentrifugasi $(0,1438-0,0956)$.Dimana formula F2,F3,F4 memiliki nilai $\mathrm{PI} \leq 0, \mathrm{I}$, hal ini mengindikasikan bahwa sampel merupakan monodisperse / I fase. Sedangkan FImemiliki nilai PI $\geq 0$, I. Nilai PI yang lebih dekat ke I menunjukkan adanya bebagai ukuran droplet dalam sediaan yang mengindikasikan bahwa sampel bukan monodisperse (Tang, et al., 20I2)

\section{KESIMPULAN}

Beradsarkan hasil penelitian dapat disimpulkan bahwa konsentrasi surfaktan berpengaruh terhadap karakteristik fisik (viskositas, ukuran droplet, zeta potensial dan polydispersity index) dengan hasil beda signifikan $(p<0,05)$ namun konsentrasi surfaktan tidak berpengaruh terhadap $\mathrm{pH}$ dengan hasil tidak berbeda nyata $(p>0,05)$.

\section{UCAPAN TERIMA KASIH}

Ucapan terimakasih ditujukan pada Akademi Farmasi Surabaya yang telah memberikan dukungan pendanaan dalam skema penelitian internal.

\section{REFERENSI}


I. E. Korkmaz, E. Gokche, Ozer, 2013. "Developement and Evaluation of Coenzym Q10 Loaded Solid Lipid Nanoparticle Hydrogel for Enhanced Dermal Delivery", Acta Pharm, 63, 517 529.

2. S. Lucangioli, V. Tripodi, 20I2. "The Importance Of The Formulation In The Effectiveness Of Coenzyme Q10 Supplementation In Mitochondrial Disease Therapy”, Der Pharmacia Sinica, 3(4), 406407.

3. P. Bhat and S. Madhav, 20I I. "A detailed review on nanoemulsion drug delivery system”, international Journal of Pharmaceutical Sciences and Research, 2(9), 2292- 2298.

4. F. Shoviantari, E. Triatiana and S. Widji, 2007. "Skin Penetration of Coenzym QIO in Nanostricture Lipid Carriers Using Olive Oil and Cetyl Palmitate", International

Journal of Pharmaceitical and clinical Research, 9(2), |42- I45.

5. Singh, Thakur Gurjeet, and Sharma, Neha, 2016. Nanobiomaterials in cosmetics: current status and future prospects Nanobiomaterials in Galenic Formulations and Cosmetics, in Applications of Nanobiomaterials, 149-174.

6. S.M. Dizaj, 20I3. "Preparation and study of vitamin A palmitate microemulsion drug delivery system and investigation of co-surfactant effect". Journal Of Nanostructure in Chemistry, 3, 59.

7. Y.P. Khor, S.P. Koh and K. Long, 2014. "A Comparative Study of the hysicochemical Properties of a Virgin Coconut Oil Emulsion and Commercial Food Supplement Emulsions", Journal Molecules, 19, 9187-9202.

8. Wulansari, S.A, R.Sumiyani and N.L.D. Aryani, 2019. Pengaruh Konsentrasi Surfaktan Terhadap Karakteristik Fisik Nanoemulsi Dan Nanoemulsi Gel Koenzim Q10. Jurnal Kimia Riset, Volume 4 No. 2.

9. M. Saifullah, A. Ahsan, M.R.I. Shishir, 2016. Production, stability and application of micro- and nanoemulsion in food production and the food processing industry, In Emulsions; Academic, Press: Cambridge, MA, USA, 405-442.

10. M. Kakoty, S.B. Gogoi, 2018. "Evaluation of surfactant formulation for EOR in some depleted oil felds of upper Assam". In: Sustainability issues in environmental geotechnics, Springer Nature, Proceedings of the 2nd GeoMEast: international congress and exhibition, 57-75.

II. Guan, Y J.Wu and Q.Zhong, 2016. Eugenol improves physical and chemical stabilities of nanoemulsions loaded with $\beta$ - carotene, Food Chem, 194, 787- 796.

12. Haidar, I, I.H. Harding, I.C. Bowater, D.S. Eldridge and W.N. Charman, 2017. "The role of lecithin degradation on the $\mathrm{pH}$ dependent stability of halofantrine encapsulated fat nano-emulsions", Int. J. Pharm., 528, 524-535.

13. Chuacharoen, T, P. Sehanat and M.S. Cristina, 2019. "Effect of surfactant concentrations on physicochemical properties and functionality of curcumin nanoemulsions under conditions relevant to commercial utilization", Journal Molecules, 24, 2744.

14. Tang, S.Y, S. Manickam, T.k. Wei and B. Nashiru, 2012. "Formulation development and optimization of a novel Cremophore EL-based nanoemulsion using ultrasound cavitation", Ultrason, Sonochem, 19, 330-345. 